\title{
Electrocatalytic Oxidation of L-cysteine by Adamantane Ester Schiff Base Nickel Complexes
}

\author{
Hao Wang ${ }^{1}$, Zheng Liu ${ }^{1, *}$, Qiuqun Liang ${ }^{1}$, Guo-Cheng Han ${ }^{2, *}$, Peng Guo ${ }^{1}$, Xinqiao Lao ${ }^{1}$, \\ Shufen Zhang ${ }^{1,3}$, Zhencheng Chen ${ }^{2}$, Ruosheng Zeng ${ }^{2}$ \\ ${ }^{1}$ College of Chemical and Biological Engineering, Guilin University of Technology, Guilin \\ 541004, P.R. China \\ ${ }^{2}$ School of Life and Environmental Sciences, Guilin University of Electronic Technology, \\ Guilin, 541004, P.R. China \\ ${ }^{3}$ State Key Laboratory of Fine Chemicals, Dalian University of Technology, Dalian 116024, P. \\ R. China \\ *E-mail: lisa4.6@163.com, hangc1981@163.com
}

doi: $10.20964 / 2018.11 .37$

Received: 12 January 2018 / Accepted: 23 April 2018 / Published: 1 October 2018

\begin{abstract}
A p-aldehyde benzoic acid adamantine ester (D1), 4-formyl benzoic acid adamantane ester shrinking o-aminophenol Schiff base (D2) and its nickel complexes (D3) were synthesized and characterized by thermogravimetric analysis, $\mathrm{H}^{1}-\mathrm{NMR}$ and UV-Vis spectrum. A glassy carbon electrode was chemically modified by adamantine esters Schiff base nickel complexes which was employed for determination of L-cysteine. The influences of the effective parameters such as the $\mathrm{pH}$ of supporting electrolyte, scanning rate and the time of maceration adsorption were investigated. The electrochemical responses to L-cysteine have a good linearity in the range of 0.01 and $0.08 \mathrm{mmol} / \mathrm{L}$ with the detection limit of $5.0 \mu \mathrm{mol} / \mathrm{L}$. The recovery rate was between $97.88 \%$ and $101.96 \%$ with the relative standard deviation of $3.9 \%$. Therefore, a new detection method for the L-cysteine content had been established in food based on Schiff base nickel complexes.
\end{abstract}

Keywords: Schiff base complexes; synthesize; modified electrode; L-cysteine

\section{$\underline{\text { FULL TEXT }}$}

(C) 2018 The Authors. Published by ESG (www.electrochemsci.org). This article is an open access article distributed under the terms and conditions of the Creative Commons Attribution license (http://creativecommons.org/licenses/by/4.0/). 